\title{
Coordination Behavior of 3-Ethoxycarbonyltetronic Acid towards Cu(II) and Co(II) Metal Ions
}

\author{
Giorgos Athanasellis, ${ }^{1}$ Georgia Zahariou, ${ }^{2}$ Stefanos Kikionis, ${ }^{1}$ \\ Olga Igglessi-Markopoulou, ${ }^{1}$ and John Markopoulos ${ }^{3}$ \\ ${ }^{1}$ Laboratory of Organic Chemistry, School of Chemical Engineering, National Technical University of Athens, \\ Zografou Campus, 15773 Athens, Greece \\ ${ }^{2}$ Institute of Materials Science, NCSR 'Demokritos', 15310 Aghia Paraskevi Attikis, Greece \\ ${ }^{3}$ Laboratory of Inorganic Chemistry, Department of Chemistry, University of Athens, Panepistimiopolis, 15771 Athens, Greece
}

Correspondence should be addressed to John Markopoulos, ojmark@orfeas.chemeng.ntua.gr

Received 10 October 2008; Accepted 5 November 2008

Recommended by Elena Milaeva

Tetronic acids, 4-hydroxy-5H-furan-2-ones, constitute a class of heterocyclic compounds with potent biological and pharmacological activity. The $\beta, \beta^{\prime}$-tricarbonyl moiety plays an integral role in biological systems and forms a variety of metal complexes. In this report, we present the complexation reactions of 3-ethoxycarbonyl tetronic acids with acetates and chlorides of $\mathrm{Cu}$ (II) and $\mathrm{Co}(\mathrm{II})$. These complexes have been studied by means of EPR spectroscopy and magnetic susceptibility measurements. From the obtained results, a preliminary complexation mode of the ligand is proposed.

Copyright (c) 2008 Giorgos Athanasellis et al. This is an open access article distributed under the Creative Commons Attribution License, which permits unrestricted use, distribution, and reproduction in any medium, provided the original work is properly cited.

\section{INTRODUCTION}

The chemistry of tetronic acids is a field of continuing interest. The appreciable number of tetronic acids found in nature $[1,2]$ and their very promising biological activities [3-5] prompted many research groups to attempt new methods for the synthesis of this class of heterocyclic compounds. Tetronic acids and their derivatives are present in a large number of natural products which exhibit a variety of biological and pharmacological properties. This class of heterocyclic compounds includes agglomerins A-D, ylidene tetronic acids [6], and the ATP-ase gastric inhibitors A88696C and A88696F [7], as well as aspertetronins and gregatins isolated from fungi which exhibit antibacterial and antifungal activities $[8,9]$.

The recent literature gives us a few examples of tetronic acids, both those isolated from nature and those synthesized in the laboratory. Such compounds are the CCK-B receptor antagonist tetronothiodin [10], the marine furanosesterpene natural product (18S)-variabilin [11], and the antibiotic abyssomicin C [12-14].

The coordination chemistry of tetronic acids has been investigated by many research groups in the past. Studies of complexes of oximidobenzotetronic acid complexed with $\mathrm{Fe}(\mathrm{II}), \mathrm{Co}(\mathrm{II}), \mathrm{Ni}(\mathrm{II}), \mathrm{Cu}(\mathrm{II}), \mathrm{Zn}(\mathrm{II}), \mathrm{Cd}(\mathrm{II})$, and $\mathrm{U}(\mathrm{VI})$ by conductometric and by $\mathrm{pH}$-metric titrations revealed that the metals form 1:2 (metal:ligand) complexes with the exception of $\mathrm{Fe}$ (II) and $\mathrm{Co}$ (II) complexes which form 1:3 ratios [15]. Processes for the synthesis of a $\mathrm{Pt}(\mathrm{II})$ complex with a 3-acetyl tetronic acid [16] and Pd(II) complexes involving tetronic acid derivatives [17] have been reported. Furthermore, a series of 3-acyl tetronic acids and their $\mathrm{Cu}(\mathrm{II})$ complexes, which possess a tricarbonylmethane structure, were prepared and tested for antimicrobial activity [18]. In addition, 3-(1-iminoalkyl) tetronic acids and their $\mathrm{Cu}(\mathrm{II})$ complexes were prepared and tested for inhibitory activity towards chlorophyll development of plants [18]. Finally, Xray crystallographic studies of the complexes of a dinuclear nitrogen bridged tetronic acid with $\mathrm{Cu}(\mathrm{II})$ and $\mathrm{Ni}(\mathrm{II})$ [19] showed that $\mathrm{Cu}(\mathrm{II})$ coordinates by means of two nitrogen and two oxygen atoms of the ligand and one water molecule on the top of a tetragonal pyramid. In contrast, the $\mathrm{Ni}$ (II) complex, having an extra water molecule, forms a nearly regular octahedron structure.

In the course of our research program on the synthesis of five membered heterocyclic compounds, we have developed 


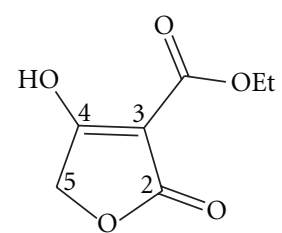

HETA

SCHeme 1: 3-Ethoxycarbonyltetronic acid.

a new advantageous methodology for the synthetic approach of functionalized tetronic [20] and thiotetronic acids [21]. The common feature of these heterocycles is the $\beta, \beta^{\prime}$ tricarbonyl system which provides them with sites available for metal complexation. Based upon the observation that tetramic acid analogues with metal ions show increased biological activities [22, 23], we have investigated the complexation of tetramic acids with several metal ions [24-29].

In this paper, we examined the complexation of 3ethoxycarbonyltetronic acid (HETA) (Scheme 1) with Cu(II) and $\mathrm{Co}$ (II) ions. We report herein our results based on the data collected after EPR spectroscopy and magnetic susceptibility measurements, and using these data, we propose structures for these complexes.

\section{EXPERIMENTAL}

\subsection{Materials and methods}

Reagent grade chemicals and solvents (Fluka, Aldrich, Acros) were used without further purification unless otherwise noted. Infrared spectra were recorded in $\mathrm{KBr}$ in the range $4000-400 \mathrm{~cm}^{-1}$ on a Nicolet Magna 560R FT-IR spectrophotometer. $\mathrm{C}, \mathrm{H}$, and $\mathrm{N}$ analyses were performed in the Organic Chemistry Laboratory (NTUA) using a EuroVector EA 3000 elemental analyzer. ${ }^{1} \mathrm{H}$ and ${ }^{13} \mathrm{C}$ NMR spectra were recorded on a Varian Gemini-2000 $300 \mathrm{MHz}$ spectrometer. The magnetic susceptibility measurements were made using a Gouy balance at room temperature using mercury tetrathiocyanatocobaltate (II), $\mathrm{Hg}\left[\mathrm{Co}(\mathrm{NCS})_{4}\right]$ as calibrant. EPR measurements were obtained at $4.2 \mathrm{~K}$ with an upgraded Bruker ER-200D spectrometer interfaced to a personal computer and equipped with an Oxford ESR 900 cryostat, an Anritsu MF76A frequency counter, and a Bruker 035M NMR gaussmeter. The perpendicular 4102ST cavity was used, and the microwave frequency was $9.41 \mathrm{GHz}$. The samples used for the EPR measurements were powders.

\subsubsection{3-Ethoxycarbonyl tetronic acid (HETA) [20]}

Powder (1.07 g, 62\%), m.p. $112-114^{\circ} \mathrm{C}$ (Anal. Found: C, 48.82; $\mathrm{H}, 4.80$. Calc. for $\left.\mathrm{C}_{7} \mathrm{H}_{8} \mathrm{O}_{5}: \mathrm{C}, 48.63 ; \mathrm{H}, 4.65 \%\right) ; v_{\max } /$ $\mathrm{cm}^{-1}(\mathrm{C}=\mathrm{O}) 1761,1651, \quad(\mathrm{C}=\mathrm{C}) 1605 ; \delta_{\mathrm{H}}\left(\mathrm{DMSO}-d_{6}\right) 1.20$ $\left(3 \mathrm{H}, \mathrm{t} J=7.5 \mathrm{~Hz}, \mathrm{COOCH}_{2} \mathrm{CH}_{3}\right), 4.14(2 \mathrm{H}, \mathrm{q} J=7.5 \mathrm{~Hz}$, $\left.\mathrm{COOCH}_{2} \mathrm{CH}_{3}\right), 4.68\left(2 \mathrm{H}, \mathrm{s}, \mathrm{CH}_{2}\right.$ ring $) ; \delta_{\mathrm{C}}\left(\mathrm{DMSO}-d_{6}\right) 14.3$ $\left(\mathrm{COOCH}_{2} \mathrm{CH}_{3}\right), \quad 59.2\left(\mathrm{COOCH}_{2} \mathrm{CH}_{3}\right), \quad 66.5(\mathrm{C}-5), 91.9$ (C-3), 161.1 (C-6), 169.5 (C-2), 186.1 (C-4).

\subsection{2. $[C u(E T A)(O A C)](1)(A c=$ acetyl)}

A methanolic solution $(12 \mathrm{~mL})$ of the ligand $(2.5 \mathrm{mmol})$ was added to a refluxing methanol solution $(30 \mathrm{~mL})$ of $\mathrm{Cu}(\mathrm{OAc})_{2} \cdot \mathrm{H}_{2} \mathrm{O}(2.5 \mathrm{mmol})$. The resulting solution was refluxed for 2 hours. The solution was evaporated to a small volume and the deposited precipitate was collected by filtration, washed with cold methanol, diethylether and dried in vacuo over $\mathrm{P}_{2} \mathrm{O}_{5}$. Powder $(0.53 \mathrm{~g}, 72 \%), \mu_{\text {eff }} 2.08 \mu_{\mathrm{B}}$; (Anal. Found: C, 36.82; H, 3.67. Calc. for $\mathrm{C}_{9} \mathrm{H}_{10} \mathrm{O}_{7} \mathrm{Cu}: \mathrm{C}$, $36.70 ; \mathrm{H}, 3.41) ; v_{\max } / \mathrm{cm}^{-1}(\mathrm{C}=\mathrm{O}$ and $\mathrm{C}=\mathrm{O}) 1724 \mathrm{~s}, 1634 \mathrm{~s}$, $1554 \mathrm{~s}, 1497 \mathrm{~s}, 1402 \mathrm{~m},(\mathrm{Cu}-\mathrm{O}) 525 \mathrm{w}, 477 \mathrm{w}$.

\subsection{3. $\left[\mathrm{Cu}(E T A)(\mathrm{OAC}) \cdot \mathrm{H}_{2} \mathrm{O}\right]_{2}(2)(\mathrm{Ac}=$ acetyl)}

A methanolic solution $(12 \mathrm{~mL})$ of the ligand $(1.9 \mathrm{mmol})$ was added to a refluxing methanol solution $(15 \mathrm{~mL})$ of $\mathrm{Cu}(\mathrm{OAc})_{2} \cdot \mathrm{H}_{2} \mathrm{O}(0.95 \mathrm{mmol})$. The resulting solution was refluxed for 2 hours. The solution was evaporated up to a small volume of the solvent and the deposited precipitate was collected by filtration, washed with cold methanol, diethylether, and dried in vacuo over $\mathrm{P}_{2} \mathrm{O}_{5}$. Powder $\left(0.25 \mathrm{~g}, 90 \%\right.$ ), $\mu_{\text {eff }} 1.63 \mu_{\mathrm{B}}$; (Anal. Found: C, 34.97; H, 3.67. Calc. for $\mathrm{C}_{18} \mathrm{H}_{24} \mathrm{O}_{16} \mathrm{Cu}_{2}$ : C, 34.67; $\mathrm{H}$, $3.85) ; v_{\max } / \mathrm{cm}^{-1}(\mathrm{OH}) 3542 \mathrm{br}, 3444 \mathrm{br},(\mathrm{C}=\mathrm{O}$ and $\mathrm{C}=\mathrm{C})$ $1726 \mathrm{~s}, 1635 \mathrm{~s}, 1557 \mathrm{~s}, 1499 \mathrm{~s}, 1441 \mathrm{~m}, 1403 \mathrm{~m},(\mathrm{Cu}-\mathrm{O}) 523 \mathrm{w}$, 475w.

\subsection{4. $\left[\mathrm{Cu}(\mathrm{ETA})_{2} \cdot\left(\mathrm{H}_{2} \mathrm{O}\right)_{2}\right](3)$}

A methanolic solution $(12 \mathrm{~mL})$ of the ligand $(2.0 \mathrm{mmol})$ was added to a refluxing methanol solution $(10 \mathrm{~mL})$ of $\mathrm{CuCl}_{2} \cdot 2 \mathrm{H}_{2} \mathrm{O}(1.0 \mathrm{mmol})$. The resulting solution was refluxed for 2 hours. The solution was evaporated to a small volume and the deposited precipitate was collected by filtration, washed with cold methanol, diethylether, and dried in vacuo over $\mathrm{P}_{2} \mathrm{O}_{5}$. Light blue powder $(0.27 \mathrm{~g}, 64 \%)$, $\mu_{\text {eff }} 2.17 \mu_{\mathrm{B}}$; (Anal. Found: C, 38.22; H, 3.78. Calc. for $\mathrm{C}_{14} \mathrm{H}_{16} \mathrm{O}_{11} \mathrm{Cu}$ : C, 38.04; H, 4.07); $v_{\max } / \mathrm{cm}^{-1}(\mathrm{OH}$ ) 3540br, 3436br, 3276br, $(\mathrm{C}=\mathrm{O}$ and $\mathrm{C}=\mathrm{C}) 1724 \mathrm{~s}, 1635 \mathrm{~s}$, $1558 s, 1498 s,(\mathrm{Cu}-\mathrm{O}) 526 \mathrm{w}, 467 \mathrm{w}$.

\subsection{5. $\left[\mathrm{Co}(\mathrm{ETA})(\mathrm{OAc}) \cdot \mathrm{CH}_{3} \mathrm{OH}\right](4)(\mathrm{Ac}=$ acetyl)}

A methanolic solution $(5 \mathrm{~mL})$ of the ligand $(1.3 \mathrm{mmol})$ was added to a refluxing methanol solution $(10 \mathrm{~mL})$ of $\mathrm{Co}(\mathrm{OAc})_{2} \cdot 4 \mathrm{H}_{2} \mathrm{O} \quad(1.3 \mathrm{mmol})$. The resulting solution was refluxed for 2 hours. The solution was evaporated to a minimal volume and the deposited precipitate was collected by filtration, washed with cold methanol, diethylether, and dried in vacuo over $\mathrm{P}_{2} \mathrm{O}_{5}$. Powder $(0.26 \mathrm{~g}, 62 \%), \mu_{\text {eff }} 4.96 \mu_{\mathrm{B}}$; (Anal. Found: $\mathrm{C}, 37.16 ; \mathrm{H}, 4.04$. Calc. for $\mathrm{C}_{10} \mathrm{H}_{14} \mathrm{O}_{8} \mathrm{Co}$ : C, 37.38; $\left.\mathrm{H}, 4.36\right)$; $v_{\max } / \mathrm{cm}^{-1}(\mathrm{OH}) 3466 \mathrm{br}, 3281 \mathrm{br}, \quad(\mathrm{C}=\mathrm{O}$ and $\mathrm{C}=\mathrm{C}) 1711 \mathrm{~s}$, $1651 \mathrm{~s}, 1567 \mathrm{~s}, 1492 \mathrm{~s}, 1441 \mathrm{~m}, 1400 \mathrm{~m},(\mathrm{Co}-\mathrm{O}) 528 \mathrm{w}, 432 \mathrm{w}$. 


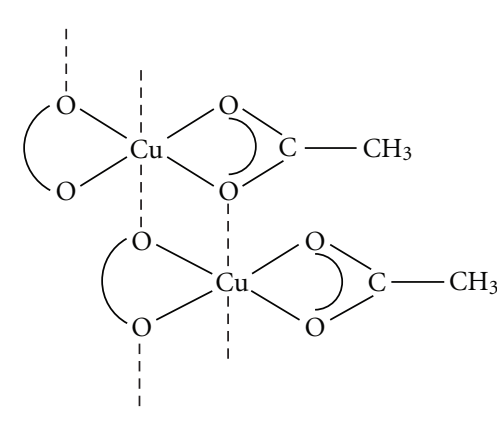

1<smiles>OC1(O)OCCO1</smiles>

3<smiles>CC12OC3(C)OC(O)(O1)OC(O)(O3)C(O)(O)O2</smiles>

2

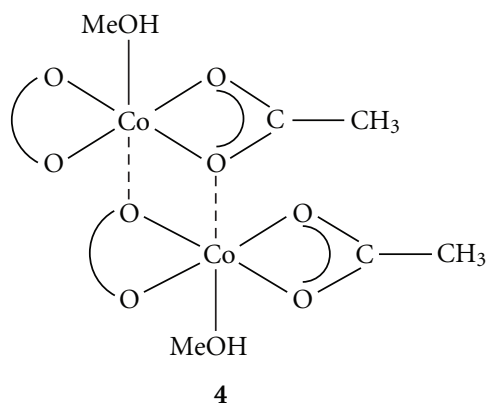

SCHEME 2

\section{RESULTS AND DISCUSSION}

The complexes $\mathrm{M}_{u}(\mathrm{OAc})_{x}(\mathrm{ETA})_{y}\left(\mathrm{H}_{2} \mathrm{O}\right)_{z}(\mathrm{MeOH})_{w}$ (where in $1, \mathrm{M}=\mathrm{Cu}, u=1, x=1, y=1, z=0, w=0 ; 2$, $\mathrm{M}=\mathrm{Cu}, u=2, x=2, y=2, z=2, w=0 ; 3, \mathrm{M}=\mathrm{Cu}, u=$ $1, x=0, y=2, z=2, w=0 ; 4, \mathrm{M}=\mathrm{Co}, u=2, x=2$, $y=2, z=0, w=2$ (Scheme 2) were prepared by reaction of the appropriate acetate salt $\mathrm{M}(\mathrm{OAc})_{2} \cdot x \mathrm{H}_{2} \mathrm{O}(x=1$, and 4 for compounds $1,2,4$ ) or chloride salt $\mathrm{MCl}_{2} \cdot x \mathrm{H}_{2} \mathrm{O}$ (for compound $3, \mathrm{M}=\mathrm{Cu}, x=2$ ) and HETA in $\mathrm{MeOH}$ under reflux by simply changing the metal:ligand ratio.

The complexes were isolated as powders following evaporation of the mixture to a minimum volume. The products were stable in the normal laboratory atmosphere and soluble in warm $\mathrm{MeOH}$. An interesting feature in the synthesis of complexes was the impossibility of isolating a complex of the "core formula" $\mathrm{M}(\mathrm{ETA})_{2}$ when we used $\mathrm{M}(\mathrm{OAc})_{2} x \mathrm{H}_{2} \mathrm{O}$ :HETA in a $1: 2$ ratio; the only isolable compounds were $\mathrm{M}(\mathrm{OAc})(\mathrm{ETA})$ complexes.

The IR spectra of the metal complexes 1-4 show the $\nu(\mathrm{C}=\mathrm{O})$ lactam and $\nu(\mathrm{C}=\mathrm{O})$ diketone characteristic bands shifted to lower wave numbers with respect to those of the free ligands confirming that two oxygen atoms are involved in the coordination sphere of the metal [30]. New bands at higher frequencies $\left(\sim 3550, \sim 3450, \sim 3300 \mathrm{~cm}^{-1}\right)$ appeared when the ligands were complexed to the metal ions (data not shown). These bands can be attributed to the stretching vibrations of the $\mathrm{OH}$ group from coordinated water or methanol molecules.

Since the IR spectra gave evidence that the metals were successfully complexed with HETA via oxygen atoms, we performed magnetic susceptibility studies to gain initial information about the spin states of the metal centers. The magnetic moments at room temperature of $\mathrm{Cu}$ (II) complexes 1,2 and 3 (2.08 BM, $1.63 \mathrm{BM}$, and $2.17 \mathrm{BM}$, resp.) indicated that no reduction to $\mathrm{Cu}(\mathrm{I})$ had occurred, whereas that of $\mathrm{Co}(\mathrm{II})$ complex 4 (4.96 BM) was characteristic of octahedral stereochemistry. The complexes $\mathbf{1}$ and $\mathbf{3}$ with $\mathrm{d}^{9}$ configuration of the central atom are magnetically diluted systems and they have the expected values [27]. However, for the complex 2 , with $\mu_{\text {eff }}=1.63 \mathrm{BM}$, the observed value was somewhat less than the spin only value for an $S=1 / 2$ system and noticeably less than that expected for a magnetically isolated $\mathrm{Cu}(\mathrm{II})$ system [31]. This behavior may be attributed to the presence of weak intermolecular interactivity (possibly involving a hydrogen bonding network), but variable 


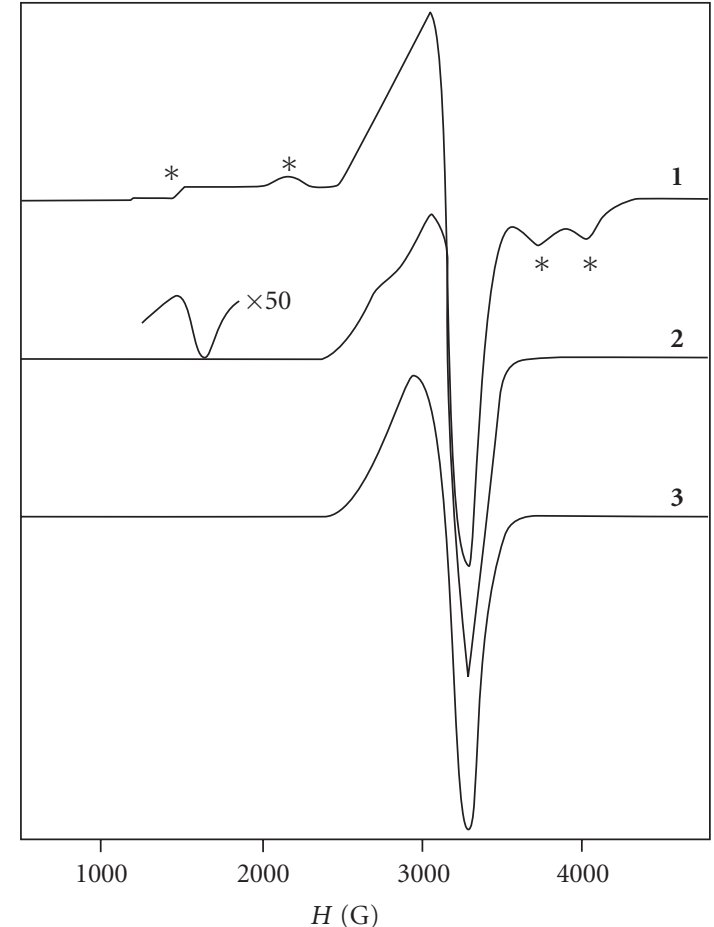

FIgURE 1: X-band spectrum of compounds 1,2, and 3. EPR conditions: microwave frequency $9.407 \mathrm{GHz}$, temperature $4.2 \mathrm{~K}$, mod. ampl. $8 \mathrm{Gpp}$, microwave power $8.2 \mathrm{~mW}$, sweep time 200 seconds, t.c.: 300 milliseconds. The asterisks $(*)$ indicate unique peaks characteristic for compound $\mathbf{1}$.

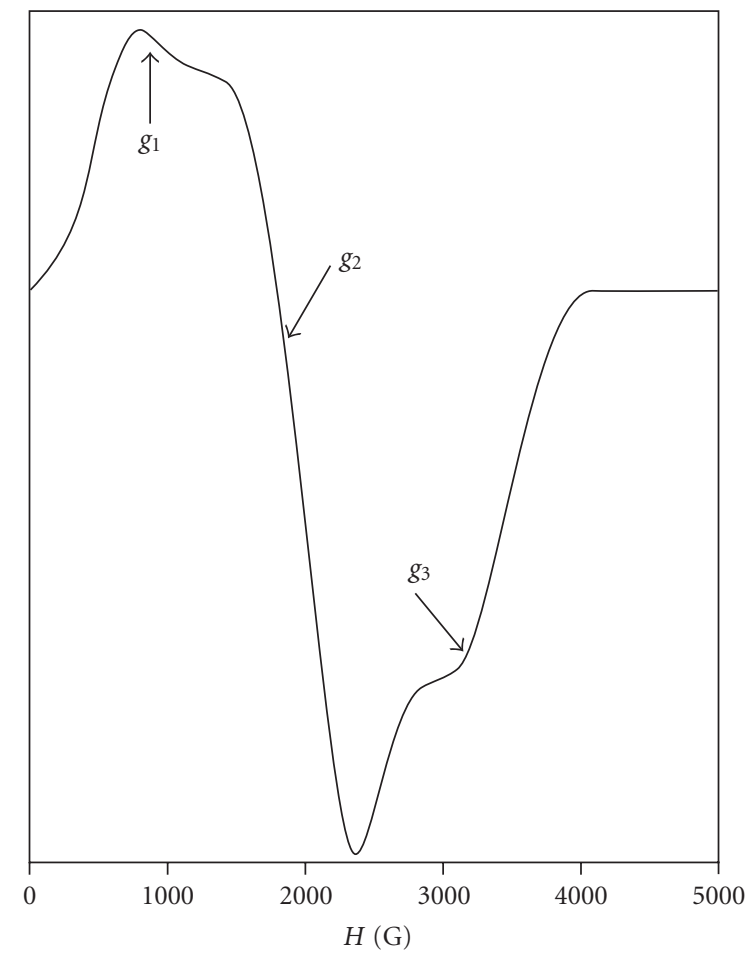

FIGURE 2: X-band spectrum of compound 4. EPR conditions: microwave frequency $9.407 \mathrm{GHz}$, temperature $4.2 \mathrm{~K}$, mod. ampl. 8 Gpp, microwave power $0.6 \mathrm{~mW}$, sweep time 200 seconds, t.c.: 300 milliseconds. The arrows indicate regions of $g$ anisotropy. temperature measurements will be required to quantify such effects [32]. The study of these effects is currently in progress in our laboratory.

The EPR spectra of compounds 1, 2 and 3 were recorded at $4.2 \mathrm{~K}$ (Figure 1). For compound 1, the spectrum exhibited two sets of signals. The first set consisted of four peaks at 1636G, 2170G, 3715G, and 4010G (indicated by asterisks, Figure 1), while the second signal defined an asymmetric feature at the region 2507-3528G.

The presence of the first set of signals indicates the population of an $S=1$ triplet state which is characteristic of dinuclear $\mathrm{Cu}$ (II) systems [33]. The spin Hamiltonian for a triplet state is given by the following equation [34]: $\hat{H}=$ $g \cdot \mu_{B} \cdot H \cdot \hat{S}+D \cdot\left[S_{z}^{2}-(1 / 3) \cdot s \cdot(s+1)\right]+E \cdot\left(S_{x}^{2}-S_{y}^{2}\right)$.

Here, $D$ and $E$ are the zero field splitting parameters, $\mu_{B}$ is the Bohr magneton, and $x, y, z$ are the principal axes. According to Wasson et al. [35] for the case of a rhombic symmetry $(E \neq 0)$, two transitions are allowed by the transition rule $\left(\Delta m_{s}= \pm 1\right)$ along each principal direction, and therefore six resonance fields can be determined. In axial symmetry $(E=0)$, four $\Delta m_{s}= \pm 1$ transitions are allowed. These four resonance fields are given by the following equations:

$$
\begin{aligned}
H_{z^{1}} & =\left(\frac{g_{e}}{g_{z}}\right) \cdot\left(H_{0}-D^{\prime}\right), \\
H_{x y^{1}}^{2} & =\left(\frac{g_{e}}{g_{x y}}\right)^{2} \cdot H_{0} \cdot\left(H_{0}-D^{\prime}\right), \\
H_{x y^{2}}^{2} & =\left(\frac{g_{e}}{g_{x y}}\right)^{2} \cdot H_{0} \cdot\left(H_{0}+D^{\prime}\right), \\
H_{z^{2}} & =\left(\frac{g_{e}}{g_{z}}\right) \cdot\left(H_{0}+D^{\prime}\right),
\end{aligned}
$$

where $H_{0}=h \cdot \nu / g \cdot \mu_{B}$ and $D^{\prime}=D / g \cdot \mu_{B}$.

The signals centered at 1636G, 2170G, 3715G, and $4014 \mathrm{G}$, assigned to the resonance fields $H_{z^{1}} H_{x y^{1}} H_{x y^{2}} H_{z^{2}}$, respectively, are indicative of copper species in a tetragonally distorted octahedral environment. From the above equations of four $\Delta m_{s}= \pm 1$ transitions, the calculated parameters are the following: $D=0.13 \mathrm{~cm}^{-1}, g_{z}=2.35, g_{x y}=2.2$. At higher temperatures, the four resonance fields disappeared (data not shown). These effects, together with the small magnitude of the $D$ value, indicated weak interactions (mainly dipolar) between $\mathrm{Cu} \cdots \mathrm{Cu}$ ions. However, the features at the region 2507-3528G consisted of a derivative at $g \sim 2.13$ and a shoulder at $g \sim 2.45$. This set of signals was characteristic of a spin doublet $S=1 / 2$ with an axial symmetry. We assigned these signals to mononuclear $\mathrm{Cu}$ (II) species in a tetragonally distorted octahedral environment with $g_{/ /}=2.45$ and $g_{\perp}=2.13$. The fact that $g_{/ /}>g_{\perp}$ was consistent with a $d_{x^{2}-y^{2}}$ orbital ground state of the copper ion.

The spectrum of compound 2 consists mainly of a derivative line at $g \sim 2.1$, and an absorption peak at $g \sim 2.5$. We assigned these features to an axial $S=1 / 2$ species with $g_{/ /}=2.5$ and $g_{\perp}=2.1$, attributed to a monomer copper center. The fact that $g_{/ /}>g_{\perp}$ suggests that the unpaired 
electron is localized in the $d_{x^{2}-y^{2}}$ orbital. Moreover, the presence of a weak signal at $\sim 1600 \mathrm{G}$, often encountered in several copper complexes [36], is attributed to $\Delta m_{s}= \pm 2$ transition, owing to $S=1$ triplet state population. This signal indicated the existence of the dinuclear species of this copper compound.

The EPR spectrum from compound 3 exhibited an asymmetric feature at the region 2330-3650G, which was assigned to a mononuclear copper complex. The asymmetric form of this signal indicated $g$ anisotropy, with $g_{\perp}=2.1$. The $g_{/ /}$component is not well resolved. The absence of signals characteristic for the $S=1$ population indicated that dinuclear species of this compound does not exist.

The EPR spectrum of compound 4 , recorded at $4.2 \mathrm{~K}$, is dominated by one resonance derivative line at $g_{2}=3.5$, as well as signals at $g_{1}=8.3$ and $g_{3}=2.17$ (Figure 2). These signals are characteristics of high-spin $(S=3 / 2)$ cobalt ion, whose spectroscopic states are separated. The splitting of spectroscopic states of a $\mathrm{d}^{7}$ configuration in coordination complexes results in two general patterns, either in an orbitally nondegenerate ground state $\left({ }^{4} \mathrm{~A}_{2}\right)$, as may be found in tetra- and penta-coordinate sites, or in an orbitally degenerated ground state $\left({ }^{4} \mathrm{~T}_{1}\right)$ in which the orbital levels are separated by spin-orbit coupling, as in cases of high symmetry crystal field [37]. The magnetic moment of $\mathrm{Co}(\mathrm{II})$ for compound $4\left(4.96 \mu_{\mathrm{B}}\right)$ is characteristic ofoctahedral stereochemistry, suggesting that its ground state is the orbitally degenerate ${ }^{4} \mathrm{~T}_{1}$. The combined effects of spin-orbit coupling and distortion of the crystal field from high symmetry lead to a series of Kramer doublets $m_{s}= \pm 1 / 2, m_{s}= \pm 3 / 2$. The ${ }^{4} \mathrm{~T}_{1}$ ground state is split into a series of levels approximately described by fictitious orbital angular momentum $L=1$ and the corresponding $J$ values of $1 / 2\left(m_{j}= \pm 1 / 2\right), 3 / 2\left(m_{j}=\right.$ $\pm 1 / 2, \pm 3 / 2)$, and $5 / 2\left(m_{j}= \pm 1 / 2, \pm 3 / 2, \pm 5 / 2\right)$. The presence of the three $g$ values of the EPR spectrum indicated $g$ anisotropy, which may be assigned to the above combined effects.

\section{CONCLUSIONS}

The isolated complexes of $\mathrm{Cu}$ (II) and $\mathrm{Co}$ (II) acetates with HETA in 1:1 ratio have octahedral stereochemistry with bidentate co-ordination through $\mathrm{O}(4)$ and $\mathrm{O}(6)$ of the tetronate ring and structures of the general formula $\mathrm{M}(\mathrm{OAc})_{x}(\mathrm{ETA})_{y}\left(\mathrm{H}_{2} \mathrm{O}\right)_{z}(\mathrm{MeOH})_{w}$. The chloride $\mathrm{Cu}(\mathrm{II})$ complex 3 with HETA in 1:2 ratio has octahedral stereochemistry and a structure of the formula $\mathrm{M}(\mathrm{ETA})_{2} \cdot 2 \mathrm{H}_{2} \mathrm{O}$. Both $\mathrm{Cu}(\mathrm{II})$ complexes 1 and 2 showed the presence of two sets of EPR signals indicating an inhomogenity of centers; some of them point to a mononuclear structure, while the others adopt a dinuclear structure [38]. Moreover, EPR studies for compounds $\mathbf{3}$ and $\mathbf{4}$ showed mononuclear and dinuclear structures, respectively. In summary, we have prepared a plausible model for the coppercobalt $\beta, \beta^{\prime}$-tricarbonyl coordination compounds. Our proposed model may help define some of the unusual features associated with copper and cobalt metallobiochemistry.

\section{ACKNOWLEDGMENTS}

The authors wish to thank Dr. Vasilis Petrouleas and Dr. Yiannis Sanakis (Institute of Materials Science, NCSR "Demokritos") for their advice and helpful discussions in the final stages of this work. The fifth author would like to thank the National and Kapodistrian University of Athens for the financial support (special account for research grant no. 70/4/3337). The first author is grateful to the Greek State Scholarships Foundation for a postdoctoral fellowship.

\section{REFERENCES}

[1] G. Pattenden, "Natural 4-ylidenebutenolides and 4ylidenetetronic acids," Fortschritte der Chemie Organischer Naturstoffe, vol. 35, pp. 133-198, 1978.

[2] A. L. Zografos and D. Georgiadis, "Synthetic strategies towards naturally occurring tetronic acids," Synthesis, vol. 2006, no. 19, pp. 3157-3188, 2006.

[3] P. M. Booth, C. M. J. Fox, and S. V. Ley, "Preparation of acyltetronic acids using t-butyl acetothioacetate: total synthesis of the fungal metabolites carolic, carlosic, and carlic acids," Journal of the Chemical Society, Perkin Transactions 1, pp. 121-129, 1987.

[4] R. Schobert and A. Schlenk, "Tetramic and tetronic acids: an update on new derivatives and biological aspects," Bioorganic and Medicinal Chemistry, vol. 16, no. 8, pp. 4203-4221, 2008.

[5] S. Peukert, Y. Sun, R. Zhang, et al., "Design and structureactivity relationships of potent and selective inhibitors of undecaprenyl pyrophosphate synthase (UPPS): tetramic, tetronic acids and dihydropyridin-2-ones," Bioorganic \& Medicinal Chemistry Letters, vol. 18, no. 6, pp. 1840-1844, 2008.

[6] J. Shoji, R. Sakazaki, T. Hattori, K. Matsumoto, N. Uotani, and T. Yoshida, "Isolation and characterization of agglomerins A, B, C and D," Journal of Antibiotics, vol. 42, no. 12, pp. 1729$1733,1989$.

[7] R. Bonjouklian, J. S. Mynderse, A. H. Hunt, and J. B. Deeter, "Structures of A88696C, D and F: gastric ATP-ase inhibitors," Tetrahedron Letters, vol. 34, no. 49, pp. 7857-7860, 1993.

[8] J. A. Ballantine, V. Ferrito, C. H. Hassall, and V. I. P. Jones, "Aspertetronin A and B, two novel tetronic acid derivatives produced by a blocked mutant of Aspergillus rugulosus," Journal of the Chemical Society C, no. 1, pp. 56-61, 1969.

[9] K. Kobayashi and T. Ui, "Graminin A, a new toxic metabolite from Cephalosporium gramineum nisikado \& ikata," Journal of the Chemical Society, Chemical Communications, no. 21, p. 774a, 1977.

[10] P. C. B. Page, H. Vahedi, K. J. Batchelor, S. J. Hindley, M. Edgar, and P. Beswick, "Synthesis of an isomer of the oxaspirobicyclic tetronic acid unit of the CCK-B receptor antagonist tetronothiodin," Synlett, vol. 2003, no. 7, pp. 10221024, 2003.

[11] K. Takabe, H. Hashimoto, H. Sugimoto, M. Nomoto, and H. Yoda, "First asymmetric synthesis of the marine furanosesterterpene natural product, (18S)-variabilin, employing enzymatic desymmetrization of propanediol derivatives," Tetrahedron: Asymmetry, vol. 15, no. 6, pp. 909-912, 2004.

[12] J.-P. Rath, M. Eipert, S. Kinast, and M. E. Maier, "Synthesis of the tetronate-containing core structure of the antibiotic abyssomicin C," Synlett, vol. 2005, no. 2, pp. 314-318, 2005.

[13] B. Bister, D. Bischoff, M. Ströbele, et al., "Abyssomicin C-a polycyclic antibiotic from a marine Verrucosispora strain as an 
inhibitor of the $p$-aminobenzoic acid/tetrahydrofolate biosynthesis pathway," Angewandte Chemie International Edition, vol. 43, no. 19, pp. 2574-2576, 2004.

[14] J.-P. Rath, S. Kinast, and M. E. Maier, "Synthesis of the fully functionalized core structure of the antibiotic abyssomicin C," Organic Letters, vol. 7, no. 14, pp. 3089-3092, 2005.

[15] G. S. Manku, R. D. Gupta, A. N. Bhat, and B. D. Jain, "Physicochemical investigations of some bivalent ion complexes with oximidobenzotetronic acid and their comparison with the corresponding 2-nitroso-1-naphthol complexes," Journal of the Indian Chemical Society, vol. 47, no. 8, pp. 776-782, 1970.

[16] H. Kawai, T. Imaoka, and G. Hata, "Process for the production of antitumor platinum complexes," PCT Int. Appl., WO 9634000, 1996.

[17] J. R. Lusty and P. Pollet, "Palladium complexes involving tetronic acid derivatives," Inorganica Chimica Acta, vol. 78, no. 1, pp. L7-L8, 1983.

[18] K. Tanaka, K. Matsuo, Y. Nakaizumi, et al., "Structure-activity relationships in tetronic acids and their copper(II) complexes," Chemical \& Pharmaceutical Bulletin, vol. 27, no. 8, pp. 19011906, 1979.

[19] G. Reck, B. Schultz, A. Zschunke, O. Tietze, and J. Haferkorn, "Crystal structures of nickel(II) and copper(II)-Schiffbases complexes with tetramic and tetronic acid subunits," Zeitschrift für Kristallographie, vol. 209, no. 12, pp. 969-974, 1994.

[20] G. Athanasellis, O. Igglessi-Markopoulou, and J. Markopoulos, "Novel short-step synthesis of optically active tetronic acids from chiral $\alpha$-hydroxy acids mediated by 1-hydroxybenzotriazole," Synlett, vol. 2002, no. 10, pp. 1736-1738, 2002.

[21] S. Kikionis, K. C. Prousis, A. Detsi, and O. IgglessiMarkopoulou, "A novel synthetic approach to the thiotetronic ring system, the key intermediate for thiolactomycin analogues," Arkivoc, vol. 2006, no. 12, pp. 28-37, 2006.

[22] W. O. Foye, "Role of metal-binding in the biological activities of drugs," Journal of Pharmaceutical Sciences, vol. 50, pp. 93$108,1961$.

[23] M.-H. Lebrun, P. Duvert, F. Gaudemer, A. Gaudemer, C. Deballon, and P. Boucly, "Complexation of the fungal metabolite tenuazonic acid with copper (II), iron (III), nickel (II), and magnesium (II) ions," Journal of Inorganic Biochemistry, vol. 24, no. 3, pp. 167-181, 1985.

[24] O. Markopoulou, J. Markopoulous, and D. Nicholls, "Synthesis of 3-butanoyl- and 3-benzoyl-4-hydroxy-3- pyrrolin-2ones and their complexes with metal ions," Journal of Inorganic Biochemistry, vol. 39, no. 4, pp. 307-316, 1990.

[25] M. Petroliagi, O. Igglessi-Markopoulou, and J. Markopoulos, "Complexation and spectroscopic studies of 5-benzylidene-3hexanoyl tetramic acid (BHTA) with magnesium (II), zinc (II) and barium (II) ions," Heterocyclic Communications, vol. 6, no. 2, pp. 157-164, 2000.

[26] B. T. Heaton, C. Jacob, J. Markopoulos, et al., "Rhodium(I) complexes containing the enolate of $N$-acetyl-3butanoyltetramic acid (Habta) and the crystal structure of $\left[\mathrm{Rh}(\mathrm{abta})\left\{\mathrm{P}(\mathrm{OPh})_{3}\right\}_{2}\right]$," Journal of the Chemical Society, Dalton Transactions, no. 8, pp. 1701-1706, 1996.

[27] E. Gavrielatos, C. Mitsos, G. Athanasellis, et al., "Copper(II), cobalt(II), nickel(II) and zinc(II) complexes containing the enolate of $\mathrm{N}$-acetyl-3-butanoyltetramic acid (Habta) and its phenylhydrazone derivative analogues. Crystal structure of $\left[\mathrm{Cu}(\mathrm{abta})_{2}(\mathrm{py})_{2}\right] \cdot 2 \mathrm{H}_{2} \mathrm{O}$," Journal of the Chemical Society, Dalton Transactions, no. 5, pp. 639-644, 2001.
[28] E. Gavrielatos, G. Athanasellis, O. Igglessi-Markopoulou, and J. Markopoulos, "Cationic diamineplatinum(II) complexes containing the enolate of N,3-acetyl-4-hydroxypyrrolin-2one," Inorganica Chimica Acta, vol. 344, pp. 128-132, 2003.

[29] E. Gavrielatos, G. Athanasellis, B. T. Heaton, et al., "Palladium(II)/ $\beta$-diketonate complexes containing the enolates of $\mathrm{N}$-acetyl-3-acyltetramic acids: crystal structure of the Lewis base adduct, $\left[\mathrm{Pd}(\mathrm{py})_{4}\right](\mathrm{abta})_{2}$," Inorganica Chimica Acta, vol. 351, no. 1, pp. 21-26, 2003.

[30] K. Nakamoto, Infrared and Raman Spectra of Inorganic and Co-ordination Compounds, John Wiley \& Sons, New York, NY, USA, 4th edition, 1986.

[31] B. J. Hathaway, "Evidence for out-of-the-plane bonding in axial complexes of the copper(II) ion," Structure and Bonding, vol. 14, pp. 49-67, 1973.

[32] C. Dendrinou-Samara, G. Psomas, C. P. Raptopoulou, and D. P. Kessissoglou, "Copper(II) complexes with phenoxyalkanoic acids and nitrogen donor heterocyclic ligands: structure and bioactivity," Journal of Inorganic Biochemistry, vol. 83, no. 1, pp. 7-16, 2001.

[33] I. Sougandi, R. Venkatesan, and P. S. Rao, "Single crystal EPR study of $\mathrm{Cu}^{2+}$ in cobalt ammonium phosphate hexahydrate: a case of low hyperfine coupling constant and measurement of spin-lattice relaxation times," Spectrochimica Acta Part A, vol. 60, no. 11, pp. 2653-2660, 2004.

[34] J. G. Ribas, Coordination Chemistry, Wiley-VCH, Weinheim, Germany, 2008.

[35] J. R. Wasson, C.-I. Shyr, and C. Trapp, "The spectral and magnetic properties of copper(II) cyanoacetate," Inorganic Chemistry, vol. 7, no. 3, pp. 469-473, 1968.

[36] E. K. Efthimiadou, Y. Sanakis, M. Katsarou, et al., "Neutral and cationic mononuclear copper(II) complexes with enrofloxacin: structure and biological activity," Journal of Inorganic Biochemistry, vol. 100, no. 8, pp. 1378-1388, 2006.

[37] R. L. Carlin and A. J. von Duyneveldt, Magnetic Properties of Transition Metal Compounds, chapter 1, Springer, New York, NY, USA, 1977.

[38] A. Diaz, R. Pogni, R. Cao, and R. Basosi, "EPR characterization of a series of mono- and bis-thiosemicarbazone copper(II) complexes," Inorganica Chimica Acta, vol. 275-276, pp. 552$556,1998$. 


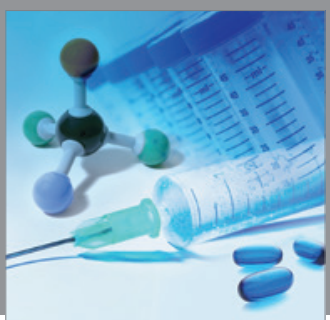

International Journal of

Medicinal Chemistry

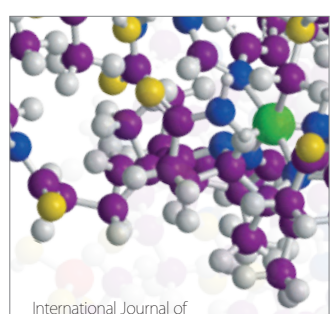

Carbohydrate Chemistry

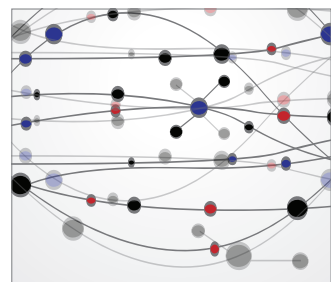

The Scientific World Journal
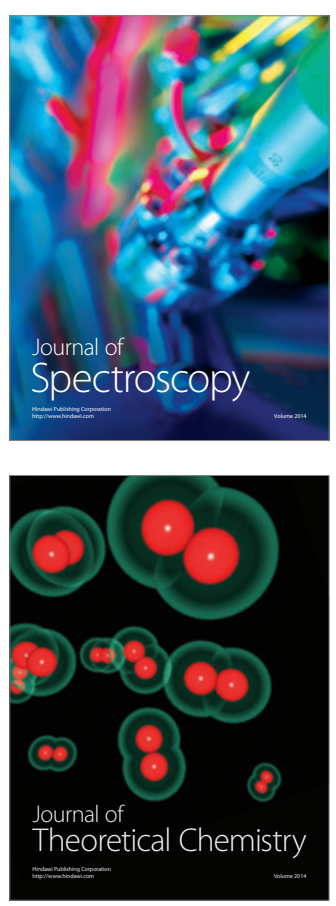
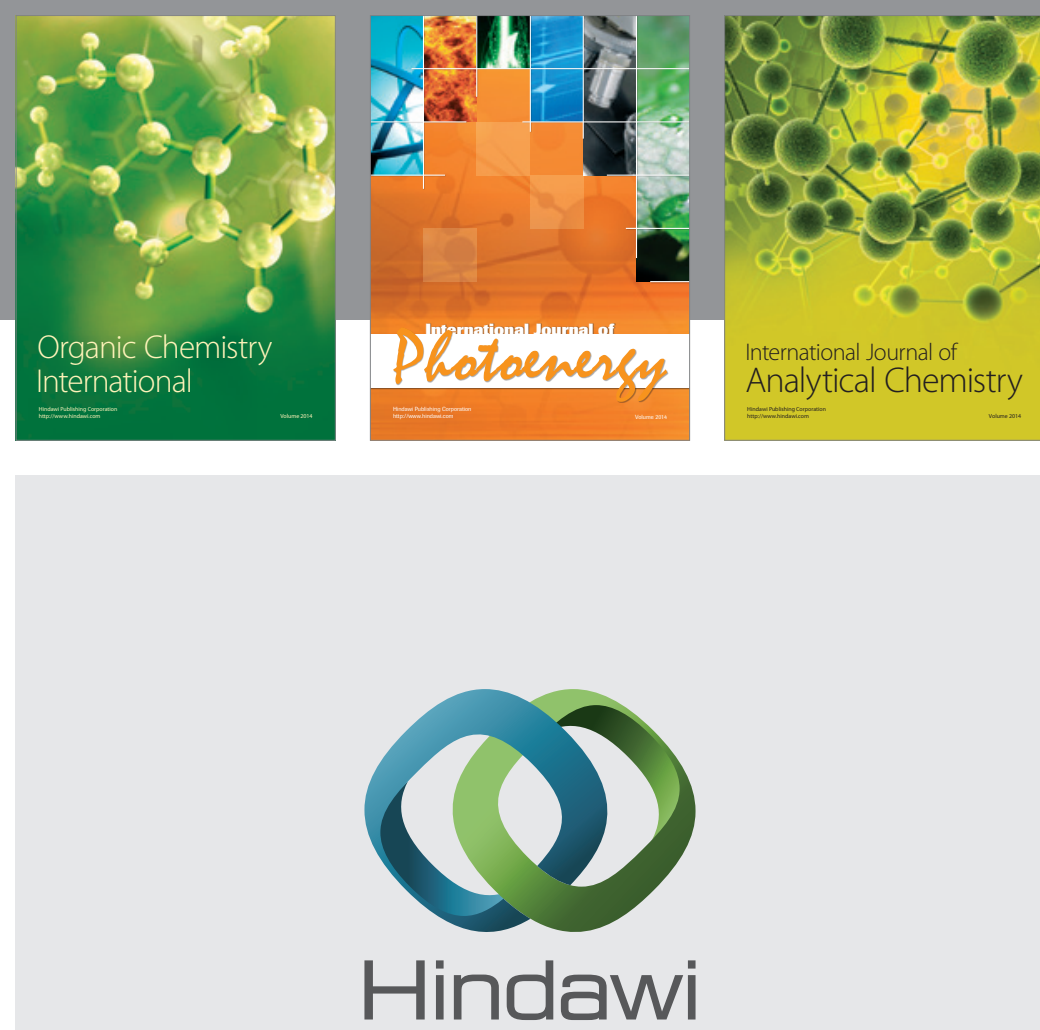

Submit your manuscripts at

http://www.hindawi.com
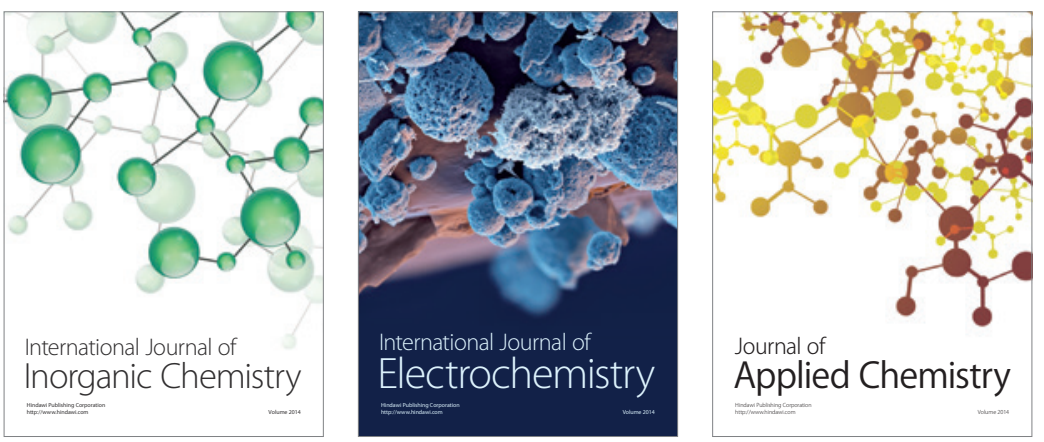

Journal of

Applied Chemistry
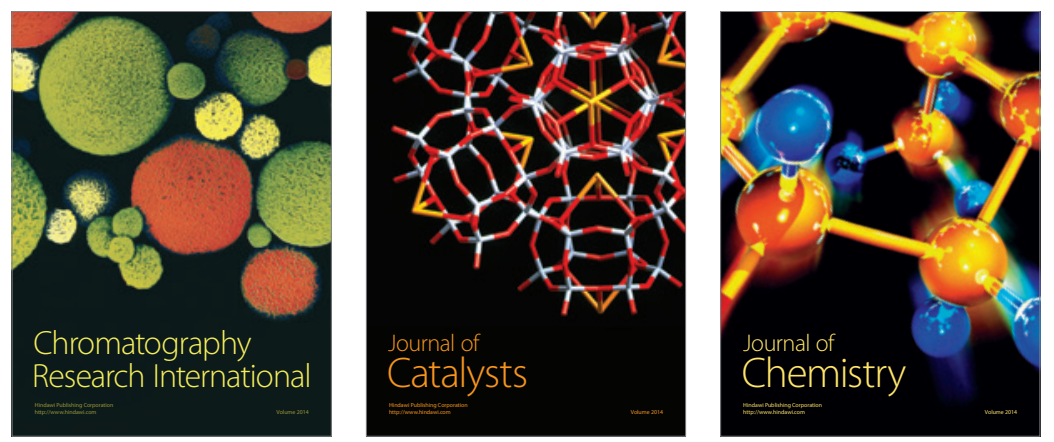
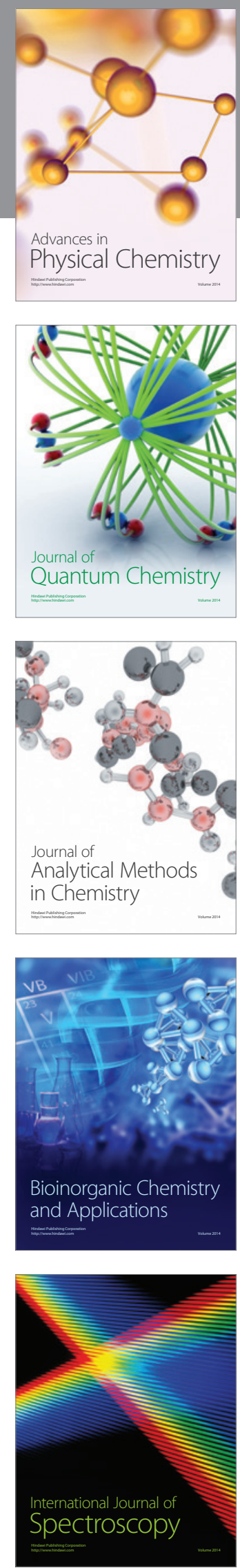